\title{
Local adjunct effect of antimicrobial photodynamic therapy for the treatment of chronic periodontitis in type 2 diabetics: split-mouth double-blind randomized controlled clinical trial
}

\author{
Nídia Cristina Castro dos Santos $^{1}$ - Naira Maria Rebelatto Bechara Andere ${ }^{1}$.

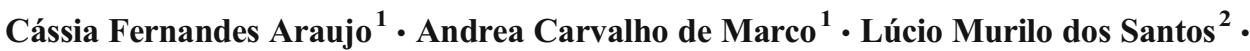 \\ Maria Aparecida Neves Jardini ${ }^{1}$ - Mauro Pedrine Santamaria ${ }^{1}$
}

Received: 2 March 2016 / Accepted: 12 July 2016 / Published online: 22 July 2016

(C) Springer-Verlag London 2016

\begin{abstract}
Diabetes has become a global epidemic. Its complications can have a significant impact on quality of life, longevity, and public health costs. The presence of diabetes might impair the prognosis of periodontal treatments due to its negative influence on wound healing. Antimicrobial photodynamic therapy (aPDT) is a local approach that can promote bacterial decontamination in periodontal pockets. The aim of this study was to investigate the local effect of adjunct aPDT to ultrasonic periodontal debridement (UPD) and compare it to UD only for the treatment of chronic periodontitis in type 2 diabetic patients. Twenty type 2 diabetic patients with moderate to severe generalized chronic periodontitis were selected. Two periodontal pockets with probing depth (PD) and clinical attachment level (CAL) $\geq 5 \mathrm{~mm}$ received UPD only (UPD group) or UPD plus adjunct aPDT (UPD + aPDT group). Periodontal clinical measures were collected and compared at baseline and 30, 90, and 180 days. After 180 days of follow-up, there were statistically significant reductions in PD from $5.75 \pm 0.91$ to $3.47 \pm 0.97 \mathrm{~mm}$ in the UPD group and from $6.15 \pm 1.27$ to $3.71 \pm 1.63 \mathrm{~mm}$ in the UPD + aPDT group. However, intergroup analysis did not reveal statistically significant differences in any of the evaluated clinical parameters $(p>0.05)$. The adjunct application of aPDT to UPD
\end{abstract}

Mauro Pedrine Santamaria

mauro.santamaria@fosjc.unesp.br

1 Department of Diagnosis and Surgery - Division of Periodontics, College of Dentistry - FOSJC, UNESP - Sao Paulo State University, Av. Eng. Francisco José Longo, 777, São José dos Campos, SP 12245-000, Brazil

2 Department of Biosciences and Oral Diagnosis, College of Dentistry - FOSJC, UNESP - Sao Paulo State University, Av. Eng. Francisco José Longo, 777, São José dos Campos, SP 12245-000, Brazil did not present additional benefits for the treatment of chronic periodontitis in type 2 diabetic patients. The ClinicalTrials. gov identifier of the present study is NCT02627534.

Keywords Diabetes mellitus · Chronic periodontitis · Periodontal pocket $\cdot$ Antimicrobial therapy $\cdot$ Photodynamic therapy $\cdot$ Low-level laser therapy

\section{Introduction}

Diabetes mellitus (DM) has emerged as a global epidemic. Its complications may significantly impair quality of life, longevity, and public health care costs [1]. The International Diabetes Federation (IDF) estimates that by 2040, 642 million people will suffer from diabetes, or approximately $10 \%$ of the world's adult population [2]. The presence of diabetes may lead to other health problems that can have a direct impact on quality of life. Among these, the most common diabetes complications are neuropathy, nephropathy, retinopathy, cardiovascular disease, and periodontal diseases.

Periodontal diseases (PDs) are characterized by inflammation in periodontal tissues, initiated by dental biofilm, that lead to the destruction of periodontal tissues and tooth loss. It is well known that diabetes increases the risk for the development and progression of periodontal diseases [1]. Type 2 diabetic individuals have a higher prevalence and severity of chronic periodontitis than normoglycemic individuals, besides having worse treatment prognoses [3].

Periodontal therapy aims at removing supra- and subgingival dental biofilm to reduce periodontal inflammatory burden, re-establish tissue homeostasis, and stop the progression of periodontal diseases. Mechanical periodontal therapy is the gold-standard treatment modality for chronic 
periodontitis and demonstrates satisfactory results [4]. The literature regarding the outcomes of mechanical therapy for treating PD in patients with type $2 \mathrm{DM}$ shows that periodontal conditions improve when conventional periodontal therapy is applied [5-8]. However, the literature reports that mechanical therapy applied alone may be insufficient to achieve a bacterial periodontopathogenic profile that is compatible with a periodontal health profile in diabetic subjects [9], which can increase the chances of failed therapy, especially in deep periodontal pockets, furcations, and complex pockets $[10,11]$. Thus, adjunctive therapies are frequently suggested to maximize mechanical therapy results, concomitant with the use of antimicrobial agents, either locally or systemically [9].

Nevertheless, the wide and undiscriminating use of systemic antibiotics to treat oral infections has led to bacterial resistance, resulting in great difficulty with controlling these infections. Still, the use of systemic antimicrobials has limitations concerning frequently reported side effects (e.g., allergies, drug interactions, headaches) and microbial resistance to the medication [12]. Besides, recent systematic reviews have shown controversial results regarding the adjunctive effect of systemic antibiotic therapy associated with scaling and root planning to treat periodontal disease in diabetic patients $[9,13]$.

Antimicrobial photodynamic therapy (aPDT) has been proposed as an adjunct therapy for scaling and root planing (SRP) for treating PD [14]. aPDT consists of the activation of a photosensitizer by laser at a specific wavelength. When sensitized, that substance releases cytotoxic oxygen and free radicals, damaging and killing bacteria. Low-level laser is applied through an optical fiber attached to a laser point inside periodontal pockets for a definite period per pocket. Several studies have shown that aPDT is effective for treating patients presenting chronic periodontitis [15-20] and aggressive periodontitis [21].

However, as long as type $2 \mathrm{DM}$ patients present a different prognosis when compared to non-diabetic patients in terms of periodontal treatment, the effects of aPDT on those patients are still unclear. A clinical trial compared SRP plus aPDT to SRP alone and to SRP plus doxycycline, and found that all of the investigated therapies were successful for treating chronic periodontitis in diabetic patients, but none of them showed statistically superior results regarding clinical periodontal parameters. aPDT was performed using $0.01 \%$ methylene blue and diode laser, with wavelength of $670 \mathrm{~nm}$, for $60 \mathrm{~s}$ [22]. Another investigation compared SRP plus aPDT to SRP alone, with the concomitant use of doxycycline in both groups. The clinical periodontal parameters were analyzed, and no statistical differences were found between the groups. aPDT was performed using $1 \%$ methylene blue and diode laser for $10 \mathrm{~s}$ per site, with wavelength of $660 \mathrm{~nm}$, irradiance of $0.028 \mathrm{~W} / \mathrm{cm}^{2}$, and fluency of $2.79 \mathrm{~J} / \mathrm{cm}^{2}$ [23]. Although these studies presented new and relevant information concerning aPDT in diabetic individuals with periodontitis, both only showed short-term results (at 3-month follow-ups) and had similar study designs (parallel groups with 15 samples each), meaning that more studies with longer follow-ups and larger samples are necessary. Thus, the aim of the present study is to evaluate the local effect of adjunct aPDT to ultrasonic periodontal debridement (UPD) for treating chronic periodontitis on type 2 diabetic patients.

\section{Materials and method}

The methodology of the present study is in accordance with the CONSORT statement [24].

\section{Study design}

This was a split-mouth, double-blind, randomized controlled clinical trial.

\section{Study population}

Subjects with type 2 diabetes and moderate to severe generalized chronic periodontitis [25] were selected from the population referred to the Department of Periodontology of São José dos Campos Dental School, UNESP - Sao Paulo State University. Detailed dental and medical records were obtained. Subjects who fulfilled the inclusion criteria were invited to participate in the study. Each subject provided informed consent after a thorough explanation of the nature, risks, and benefits of the clinical investigations. The study protocol was approved by the Institutional Review Board at São José dos Campos Dental School, UNESP - São Paulo State University (617.795). The ClinicalTrials.gov identifier of the present study is NCT02627534. The inclusion criteria were as follows: age $\geq 35$; diagnosis of type 2 diabetes for $\geq 5$ years; diabetes treatment with oral hypoglycemic agents or insulin supplementation and diet; glycated hemoglobin (HbA1c) levels from 6.5 to $11 \%$; at least 15 teeth (excluding third molars and teeth indicated for extraction); and moderate to severe generalized chronic periodontitis [25]. The exclusion criteria were the following: medical conditions that required prophylactic antimicrobial coverage; periodontal mechanical therapy in the previous 6 months; antimicrobial therapies in the previous 6 months; anti-inflammatory therapies in the previous 6 months; systemic conditions other than diabetes that could affect the progression of chronic periodontitis; current use of medication that could interfere with periodontal response to treatment; pregnancy or lactation; and smoking. 


\section{Sample size calculation}

The ideal sample size was calculated considering a mean probing depth (PD) reduction of $1 \mathrm{~mm}$ between groups, with a standard deviation of $0.8 \mathrm{~mm}$. Based on this, 17 periodontal pockets in each group would be enough to provide $95 \%$ power with a $5 \%$ significance level. Considering an attrition rate of $15 \%, 20$ periodontal pockets were included in each group [26].

\section{Initial therapy}

All patients received instructions about the relationship between chronic periodontitis and type 2 diabetes, oral hygiene, supragingival biofilm and calculus removal, the extraction of hopeless teeth, dental decay removal and provisional restoration, and the removal of overhanging restorations.

\section{Periodontal pocket selection}

After initial therapy, two sites in each patient with PD and clinical attachment level (CAL) $\geq 5 \mathrm{~mm}$ in single-rooted teeth from different quadrants were selected to receive one of the following treatments:

Control group $(n=20)$ : UPD

Test group $(n=20)$ : UPD + aPDT

\section{Randomization and allocation concealment}

Randomization was done as described: first, each selected site received a code letter. An individual who was not a member of the study used a computer-generated sequence to randomly allocate the selected sites to UPD or UPD + aPDT. This sequence was placed in sealed and opaque envelopes, with each one containing the sites and their respective treatment modalities. This step was done to blind the randomization sequence for the professional responsible for patient recruitment (MPS), treatment (NMRBA), and the clinical measures (NCCS). Besides their allocation being concealed, the patients were not aware of which sites had been selected for the control and test groups. The randomization parameters and blinding were performed according to the CONSORT statement 2010 [24].

\section{Treatment}

After randomization, all patients received ultrasonic periodontal debridement (UPD). Thus, the patients were submitted to local anesthesia and received one session of full-mouth ultrasonic debridement (Cavitron, Dentsply) with specific inserts (UI25KSF10S, Hu-Friedy). All diseased sites were instrumented in one session by a trained operator. All diseased sites were checked with a periodontal probe for complete subgingival calculus removal. After periodontal debridement, one previously selected periodontal pocket received additional aPDT.

\section{aPDT protocol}

After ultrasonic debridement, one previously randomly selected periodontal pocket received an additional aPDT application performed by a trained operator (NMRBA). One pocket with $\mathrm{PD} \geq 5 \mathrm{~mm}$ in each patient was randomly selected for aPDT. After washing the pocket with saline solution, a photosensitizer $(0.005 \%$ methylene blue - Chimiolux DMC) was applied to the bottom of the pocket in a coronal direction for $60 \mathrm{~s}$, followed by irrigation to remove excess. Then, the pocket was exposed to continuous wave diode laser irradiation for $60 \mathrm{~s}$ with a fiber optic of $600 \mu \mathrm{m}$ in diameter (Thera LaseDMC, Brazil), with wavelength of $660 \mathrm{~nm}$, power of $60 \mathrm{~mW}$, irradiance of $2.15 \mathrm{~W} / \mathrm{cm}^{2}$, total energy delivered of $3.6 \mathrm{~J}$, and fluency of $129 \mathrm{~J} / \mathrm{cm}^{2}$. Laser power and fluency were confirmed through device calibration prior to each application.

\section{Clinical parameters}

All of the clinical measures were performed by one calibrated operator (NCCS), who was blinded to the treatment allocation. The examiner participated in a calibration exercise in which the $\mathrm{PD}$ and CAL of ten patients were measured twice in a 24-h interval. Then, the measurement was submitted to intraclass correction test. The agreement for variables was $>90 \%$.

Clinical measures were performed before treatment (baseline) and 30, 90, and 180 days after treatment. The evaluated parameters were as follws: (1) robing depth (PD) (primary outcome measure); (2) CAL (secondary outcome measure); (3).gingival recession (GR); (4) bleeding on probing (BoP); (5) plaque index (PI); and (6) gingival index (GI). All of the clinical measures were assessed using a manual probe (North Carolina-Hu-Friedy).

\section{PISA index calculation}

Periodontal inflamed surface area (PISA) index calculation was performed for each selected pocket according to Nesse et al., 2008, and compared at baseline and 30, 90, and 180 days.

\section{Glycemic and systemic monitoring}

All of the patients were under medical treatment for diabetes and submitted to periodic HbAlc evaluations. Thus, the patients were asked to present $\mathrm{HbAlc}$ evaluations during the study period, and data was recorded and compared at baseline and 180 days. Data related to C-reactive protein (CRP) and body mass index (BMI) were also collected and compared at baseline and 180 days. 


\section{Statistical analysis}

The clinical parameters were computed per subject and per selected pocket. The mean and standard deviation were calculated for each parameter. The normality of the data was analyzed according to the Shapiro-Wilk test. The clinical measures were analyzed according to a variance test (repeated measures) for intra- and intergroup analysis. Glycemic monitoring data were submitted to a variance analysis for intragroup comparison.

\section{Results}

Twenty patients participated in the study, for a total of 40 periodontal pockets. All of them had two randomly selected periodontal pockets with $\mathrm{PD}$ and $\mathrm{CAL} \geq 5 \mathrm{~mm}$ to receive two different local therapies. Figure 1 shows the flow of the patients through the study. None of the patients reported adverse effects related to laser therapy, such as discomfort, burning sensation, and pain.

The sample consisted of twenty subjects with poorly controlled diabetes, with mean HbA1c serum level of $8.03 \pm$ $2.29 \%$. Fifteen subjects were women $(75 \%)$, and five were men $(25 \%)$. Their mean age was $51.60 \pm 10.05$, and they had an average of $21.20 \pm 4.51$ teeth. One patient was lost during follow-up. The data were analyzed according to intention-totreat concept. Table 1 shows the HbAlc, CRP, and BMI results at baseline and 180 days. Our patients had poorly controlled diabetes, with HbA1c $8.03 \pm 2.29 \%$ at baseline and $8.48 \pm 2.14 \%$ at 180 days, with no statistically significant differences between the times. C-reactive protein decreased from $1.04 \pm 1.40 \mathrm{mg} / \mathrm{dl}$ at baseline to $0.64 \pm 0.36 \mathrm{mg} / \mathrm{dl}$ at
Table 1 Systemic data at baseline (BL) and 180 days $(n=19)$

\begin{tabular}{lrrr}
\hline & \multicolumn{1}{l}{ BL } & \multicolumn{1}{l}{180 days } & $p$ value \\
\hline HbA1c (\%) & $8.03 \pm 2.29$ & $8.48 \pm 2.14$ & 0.6 \\
C-reactive protein (mg/dl) & $1.04 \pm 1.40$ & $0.64 \pm 0.36$ & 0.9 \\
BMI & $28.03 \pm 8.43$ & $28.36 \pm 5.26$ & 0.7 \\
\hline
\end{tabular}

Statistically significant difference (Mann-Whitney rank sum test, $p>0.05)$

180 days, but no statistically significant difference was detected. The patients remained overweight during the study, with BMI $28.03 \pm 8.43$ at baseline and $28.36 \pm 5.26$ at 180 days, with no difference in intragroup comparison $(p>0.05)$.

Data related to full-mouth parameters are presented in Table 2. All of the clinical parameters decreased from baseline to 30,90 , and 180 days, with PD, GI, PI, percentage of pockets with $\mathrm{PD} \geq 5 \mathrm{~mm}$, and percentage of pockets with $\mathrm{PD} \geq 7 \mathrm{~mm}$ being statistically significant. The mean PD changed from $4.06 \pm 0.93 \mathrm{~mm}$ at baseline to $3.14 \pm$ $0.38 \mathrm{~mm}$ at 180 days. GI and PI showed similar results at all times, with significant reduction after the study intervention. GI decreased from $54 \pm 25 \%$ at baseline to $22 \pm$ $15 \%$ at 180 days, while PI changed from $69 \pm 23 \%$ at baseline to $24 \pm 15 \%$ at 180 days. The percentages of sites with $\mathrm{PD} \geq 5 \mathrm{~mm}$ and $\mathrm{PD} \geq 7 \mathrm{~mm}$ also significantly decreased after the study intervention and continued to decrease at 90 and 180 days. The initial percentage of sites with $\mathrm{PD} \geq 5 \mathrm{~mm}$ was $34.14 \pm 18.89 \%$ and changed to $13.53 \pm 8.51 \%$ at 180 days. At baseline, the percentage of sites with $\mathrm{PD} \geq 7 \mathrm{~mm}$ was $12.52 \pm 12 \%$, decreasing to $3.05 \pm 3.15 \%$ at 180 days.

At baseline, there were no statistically significant differences for clinical parameters of the selected periodontal pockets

Fig. 1 Consort flow chart of the study

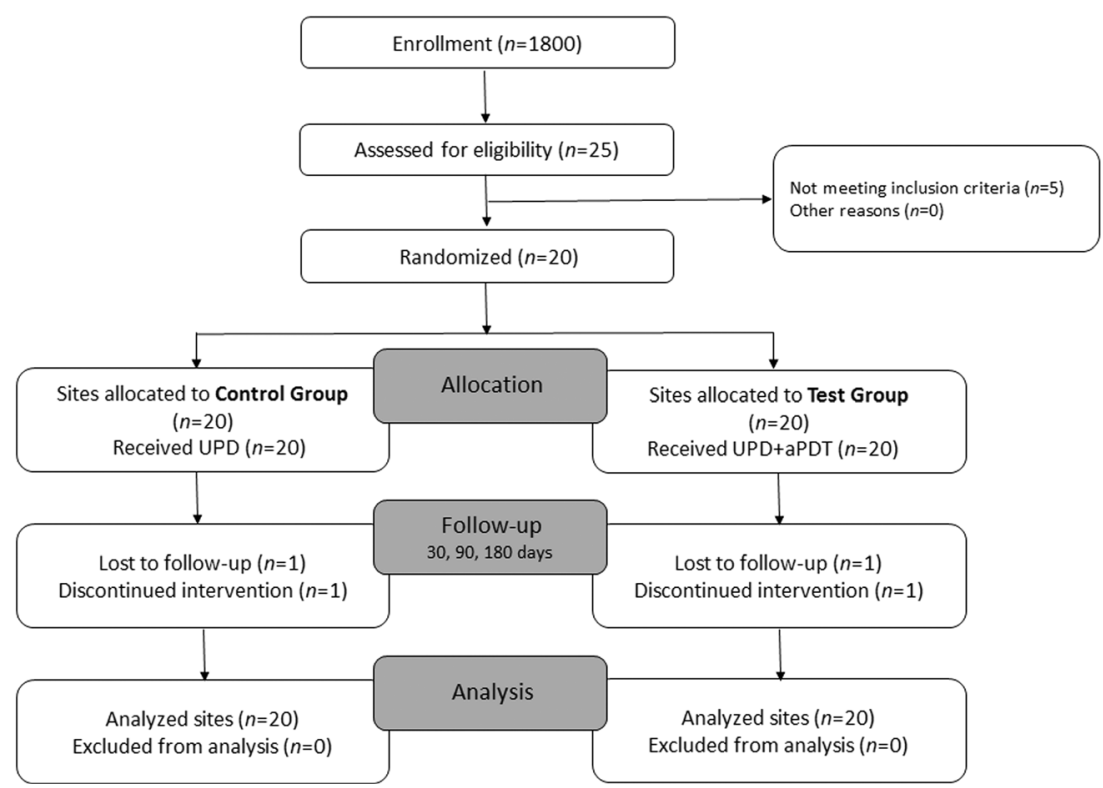


Table 2 Full-mouth clinical parameters at baseline (BL), 30, 90 , and 180 days $(n=19)$

\begin{tabular}{|c|c|c|c|c|c|}
\hline & & $\mathrm{BL}$ & 30 days & 90 days & 180 days \\
\hline Mean PD (mm) & & $4.06 \pm 0.93 \mathrm{~A}$ & $3.23 \pm 0.55 \mathrm{~B}$ & $3.16 \pm 0.48 \mathrm{~B}$ & $3.14 \pm 0.38 \mathrm{~B}$ \\
\hline PD reduction (mm) & $\Delta \mathrm{PD}$ & - & $0.84 \pm 0.86 \mathrm{~A}$ & $0.91 \pm 1.10 \mathrm{~A}$ & $0.93 \pm 0.77 \mathrm{~A}$ \\
\hline Mean CAL (mm) & & $4.54 \pm 1.28 \mathrm{~A}$ & $3.96 \pm 0.91 \mathrm{~A}$ & $3.94 \pm 1.02 \mathrm{~A}$ & $3.89 \pm 1.06 \mathrm{~A}$ \\
\hline CAL gain $(\mathrm{mm})$ & $\triangle \mathrm{CAL}$ & - & $0.58 \pm 1.33 \mathrm{~A}$ & $0.60 \pm 1.11 \mathrm{~A}$ & $0.65 \pm 0.98 \mathrm{~A}$ \\
\hline Gingival index $(\%)$ & & $54 \pm 25 \mathrm{~A}$ & $18 \pm 12 \mathrm{~B}$ & $17 \pm 7 \mathrm{~B}$ & $22 \pm 15 B$ \\
\hline Plaque index $(\%)$ & & $69 \pm 23 \mathrm{~A}$ & $25 \pm 17 \mathrm{~B}$ & $22 \pm 14 \mathrm{~B}$ & $24 \pm 15 \mathrm{~B}$ \\
\hline$\%$ sites with $\mathrm{PD} \geq 5 \mathrm{~mm}$ & & $34.14 \pm 18.89 \mathrm{~A}$ & $16.58 \pm 12.94 \mathrm{~B}$ & $15.55 \pm 10.95 \mathrm{~B}$ & $13.53 \pm 8.51 \mathrm{~B}$ \\
\hline$\%$ sites with $\mathrm{PD} \geq 7 \mathrm{~mm}$ & & $12.52 \pm 12 \mathrm{~A}$ & $4.60 \pm 5.40 \mathrm{~B}$ & $3.53 \pm 3.91 \mathrm{~B}$ & $3.05 \pm 3.15 \mathrm{~B}$ \\
\hline
\end{tabular}

Different uppercase letters represent intragroup statistically significant difference (one-way ANOVA, $p<0.05$ ) allocated to the control and test groups $(p>0.05)$. After the study intervention, both groups presented statistically significant differences in intragroup comparisons at 30, 90, and 180 days. Our primary variable, PD, decreased from $5.75 \pm$ $0.91 \mathrm{~mm}$ at baseline to $3.47 \pm 0.97 \mathrm{~mm}$ at 180 days in the control group and from $6.15 \pm 1.27 \mathrm{~mm}$ at baseline to $3.71 \pm$ $1.63 \mathrm{~mm}$ at 180 days in the test group. However, in the intergroup comparison, no statistically significant difference was detected. Mean CAL decreased from $5.95 \pm 1.03 \mathrm{~mm}$ at baseline to $4.26 \pm 1.30 \mathrm{~mm}$ at 180 days in the control group and from $6.35 \pm 1.27 \mathrm{~mm}$ at baseline to $4.61 \pm 1.92 \mathrm{~mm}$ at 180 days in the test group, with a statistically significant difference in the intragroup comparison but no significant difference in the intergroup comparison. The CAL gains were very similar between the groups, $1.58 \pm 1.40 \mathrm{~mm}$ in the control group and $1.58 \pm 1.28 \mathrm{~mm}$ in the test group, with no statistically significant difference detected. Statistical analysis also revealed significant differences for GR, BoP, percentage of pockets with $\mathrm{PD} \geq 5 \mathrm{~mm}$, and percentage of pockets with PD reduction $\geq 2 \mathrm{~mm}$ in both groups, but no significant differences between the control and test groups were detected (Table $3 ; p>0.05$ ).

The PISA index was calculated for each selected site, and the results were compared at baseline and 30, 90, and 180 days. In the control group, PISA decreased from $34.93 \pm 29.08 \mathrm{~mm}^{2}$ at baseline to $6.40 \pm 8.22 \mathrm{~mm}^{2}$ at 180 days, showing significant clinical improvement after control intervention. Likewise, in the test group, PISA changed from $42.70 \pm 33.60 \mathrm{~mm}^{2}$ at baseline to $9.90 \pm$ $11.35 \mathrm{~mm}^{2}$ at 180 days, with a significant difference in intragroup comparison. However, the intergroup comparison did not reveal a statistically significant difference for this variable (Table $3 ; p>0.05$ ).

\section{Discussion}

To the best of our knowledge, this is the first 6-month, splitmouth, randomized clinical trial to evaluate the effects of adjunct antimicrobial photodynamic therapy to ultrasonic periodontal debridement for the treatment of chronic periodontitis in type 2 diabetic patients. Our study did not detect statistically significant differences in the evaluated clinical parameters when the UPD group was compared to the UPD + aPDT group at 30, 90, and 180 days. However, in the intragroup comparison, both groups showed statistically significant changes in all of the clinical parameters. Therefore, these results suggest that a single application of aPDT may not present additional benefits to UPD for the treatment of chronic periodontitis in type 2 diabetic patients. The findings of this study are comparable to two other studies that investigated the effects of adjunct aPDT to periodontal therapy on patients with poorly controlled type 2 diabetes [22, 23]. During a 90day follow-up, neither of them found statistically significant differences in any evaluated clinical parameters between their control and test groups.

The effectiveness of adjunct aPDT to periodontal mechanical therapy is still controversial. While some investigations have demonstrated additional clinical benefits for this approach in normoglycemic patients [16, 18, 27, 28], others have failed to detect statistically significant differences in the evaluated clinical parameters [29-31]. Controversy in these findings may occur due to a great variety between protocols, differences between groups and in periodontitis severity, and different study designs.

The first clinical trial to evaluate the additional benefits of aPDT in chronic periodontitis was a split-mouth clinical trial ( $n=10$ patients) [29]. Scaling and root planing (SRP) was performed in all periodontal pockets of a randomly selected quadrant. Then, $0.005 \%$ methylene blue was rinsed, and a single application of aPDT was performed in each diseased site of this quadrant. The results were compared to those of the other quadrants, which received SRP only, aPDT only, and oral hygiene instructions only. Additional benefits of aPDT as an adjunct to SRP within a follow-up of 32 days were not observed. In 2007, Andersen et al. investigated adjunct aPDT to SRP in chronic periodontitis. Thirty-three patients with moderate to severe chronic periodontitis were allocated to three groups receiving one of the therapies (aPDT only or 
Table 3 Clinical parameters of control and test groups at baseline (BL), 30, 90, and 180 days

\begin{tabular}{|c|c|c|c|c|}
\hline Variable & Time point & UPD (control; $n=20$ ) & $\begin{array}{l}\mathrm{UPD}+\mathrm{aPDT} \\
\text { (test; } n=20)\end{array}$ & $p$ value \\
\hline \multirow[t]{4}{*}{ Mean PD (mm) } & $\mathrm{BL}$ & $5.75 \pm 0.91 \mathrm{Aa}$ & $6.15 \pm 1.27 \mathrm{Aa}$ & 0.25 \\
\hline & 30 & $3.68 \pm 0.89 \mathrm{Ab}$ & $4.11 \pm 1.40 \mathrm{Ab}$ & 0.10 \\
\hline & 90 & $3.89 \pm 0.99 \mathrm{Ab}$ & $3.78 \pm 1.61 \mathrm{Ab}$ & 0.74 \\
\hline & 180 & $3.47 \pm 0.97 \mathrm{Ab}$ & $3.71 \pm 1.63 \mathrm{Ab}$ & 0.25 \\
\hline PD reduction $(\mathrm{mm})$ & $\Delta \mathrm{PD}$ & $1.95 \pm 1.42 \mathrm{~A}$ & $2.16 \pm 1.28 \mathrm{~A}$ & 0.19 \\
\hline \multirow[t]{4}{*}{ Mean CAL (mm) } & BL & $5.95 \pm 1.03 \mathrm{Aa}$ & $6.35 \pm 1.27 \mathrm{Aa}$ & 0.33 \\
\hline & 30 & $4.37 \pm 1.60 \mathrm{Ab}$ & $4.79 \pm 2.00 \mathrm{Ab}$ & 0.24 \\
\hline & 90 & $4.37 \pm 1.42 \mathrm{Ab}$ & $4.44 \pm 1.90 \mathrm{Ab}$ & 0.54 \\
\hline & 180 & $4.26 \pm 1.30 \mathrm{Ab}$ & $4.61 \pm 1.92 \mathrm{Ab}$ & 0.28 \\
\hline CAL gain (mm) & $\triangle \mathrm{CAL}$ & $1.58 \pm 1.40 \mathrm{~A}$ & $1.58 \pm 1.28 \mathrm{~A}$ & 0.28 \\
\hline \multirow[t]{4}{*}{ Mean GR (mm) } & $\mathrm{BL}$ & $0.15 \pm 0.49 \mathrm{Aa}$ & $0.20 \pm 0.41 \mathrm{Aa}$ & 0.87 \\
\hline & 30 & $0.68 \pm 0.93 \mathrm{Aa}$ & $0.68 \pm 1.06 \mathrm{Aa}$ & 0.99 \\
\hline & 90 & $0.63 \pm 0.94 \mathrm{Aa}$ & $0.66 \pm 1.18 \mathrm{Ab}$ & 0.41 \\
\hline & 180 & $0.79 \pm 1.16 \mathrm{Ab}$ & $0.90 \pm 1.27 \mathrm{Ab}$ & 0.78 \\
\hline \multirow[t]{4}{*}{$\mathrm{BoP}(\%)$} & $\mathrm{BL}$ & $100 \mathrm{Aa}$ & $100 \mathrm{Aa}$ & \\
\hline & 30 & $37 \mathrm{Ab}$ & $26 \mathrm{Ab}$ & 0.76 \\
\hline & 90 & $37 \mathrm{Ab}$ & $37 \mathrm{Ab}$ & \\
\hline & 180 & $32 \mathrm{Ab}$ & $47 \mathrm{Ab}$ & 0.56 \\
\hline \multirow[t]{4}{*}{ Pockets with $\mathrm{PD} \geq 5 \mathrm{~mm}(\%)$} & $\mathrm{BL}$ & $100 \mathrm{Aa}$ & $100 \mathrm{Ab}$ & \\
\hline & 30 & $5.26 \mathrm{Ab}$ & $21.05 \mathrm{Ab}$ & 0.26 \\
\hline & 90 & $10.53 \mathrm{Ab}$ & $21.05 \mathrm{Ab}$ & 0.57 \\
\hline & 180 & $0 \mathrm{Ab}$ & $15.09 \mathrm{Ab}$ & 0.32 \\
\hline \multirow[t]{3}{*}{ Pockets with $\mathrm{PD}$ reduction $\geq 2 \mathrm{~mm}(\%)$} & 30 & 73.68Aa & $68.42 \mathrm{Aa}$ & 0.89 \\
\hline & 90 & $73.68 \mathrm{Aa}$ & $73.68 \mathrm{Aa}$ & \\
\hline & 180 & $73.68 \mathrm{Aa}$ & $73.68 \mathrm{Aa}$ & \\
\hline \multirow[t]{4}{*}{ PISA $\left(\mathrm{mm}^{2}\right)$} & BL & $34.93 \pm 29.08 \mathrm{Aa}$ & $42.70 \pm 33.60 \mathrm{Aa}$ & 0.19 \\
\hline & 30 & $8.63 \pm 10.88 \mathrm{Ab}$ & $8.30 \pm 11.10 \mathrm{Ab}$ & 0.91 \\
\hline & 90 & $9.10 \pm 10.66 \mathrm{Ab}$ & $10.80 \pm 10.30 \mathrm{Ab}$ & 0.70 \\
\hline & 180 & $6.40 \pm 8.22 \mathrm{Ab}$ & $9.90 \pm 11.35 \mathrm{Ab}$ & 0.23 \\
\hline
\end{tabular}

Different letters (uppercase - horizontal, lowercase - vertical) indicate statistically significant difference (twoway repeated measures - ANOVA/Tukey's test, $p<0.05$ )
SRP only) or a combination of both. aPDT was performed according to the following protocol: methylene blue $(0.005 \%)$ was applied inside periodontal pockets for $60 \mathrm{~s}$; then, a diode laser (wavelength of $670 \mathrm{~nm}$, power of $50 \mathrm{~mW}$ ) was applied for $60 \mathrm{~s}$. The patients were examined at baseline and 6 and 12 weeks. The clinical parameters were BoP, CAL, and PD. The authors reported that the combination of aPDT and SRP presented better results than aPDT only and SRP only [16]. In 2013, Luchesi et al. investigated the use of aPDT to treat class II furcation. Patients were randomly allocated to test (aPDT; $n=16$ ) and control groups (photosensitizer only, non-activated laser; $n=21$ ). SRP was performed for both groups. For the test group, a photosensitizer was applied to the bottom of the periodontal pocket and a diode laser was activated with fiber optics for $60 \mathrm{~s}$. The patients were examined at baseline and 3 and 6 months. The authors found that photodynamic therapy did not promote additional clinical benefits, although local levels of cytokines and periodontopathogens decreased [32].

In patients with poorly controlled diabetes, it is important to stress that vascular complications and impaired wound healing alter the response to conventional periodontal treatment. It seems that this impaired response is also observed when aPDT is applied. Apparently, adjunct aPDT is not effective in providing additional benefits to mechanical periodontal therapy in patients with poorly controlled diabetes. Additionally, UPD alone provided statistically significant changes in all clinical parameters, which means that this was a successful approach in our study. Mean PD, our primary variable, changed from $5.75 \pm 0.91$ to $3.47 \pm 0.97 \mathrm{~mm}$ in the selected sites. These results suggest that when adequate decontamination is achieved through mechanical periodontal therapy, aPDT is not able to provide additional benefits for periodontal treatment in diabetic patients. 
The PISA index was proposed as a method of quantifying the inflammatory burden caused by periodontal diseases to better classify periodontal diseases [33]. The PISA calculation suggests a more accurate form of estimating the damage caused to periodontal tissue. In this study, we calculated the PISA index for each selected periodontal pocket, quantified periodontal inflammation, and compared results through different follow-up times and local periodontal therapies. PISA showed similar results to those obtained through gold-standard clinical parameters, indicating that it is a reliable method of quantifying periodontal diseases.

This was a split-mouth, controlled clinical trial to investigate the effects of adjunct aPDT to UPD for treating chronic periodontitis in type 2 diabetic patients. This study design was chosen to minimize differences in host response between the study groups. Patients with poorly controlled diabetes may present metabolic variations that impact periodontal tissue and cannot be managed or controlled by periodontists (alterations due to medication, changes in eating habits, weight gain/loss, etc.)

To monitor systemic conditions that could influence diabetes and, consequently, chronic periodontitis, data concerning HbA1c, CRP, and BMI were collected and analyzed at baseline and 180 days for each patient. There were no statistically significant differences between the times, so periodontal parameters were not compromised due to the course of diabetes.

One limitation of this study is that aPDT presents a great variety of protocols, with variations in lasers, laser parameters, application protocols, and photosensitizers. However, the present study tested only one protocol. Thus, other studies investigating the effects of aPDT should be performed to establish an effective protocol, such as multiple aPDT applications, or to evaluate other photosensitizers, for treating chronic periodontitis in type 2 diabetic patients. Another limitation concerns the root morphology of the selected sites. In our study, we only selected periodontal pockets in single-rooted teeth as a means of standardization. As long as this type of sites can be easily decontaminated by mechanical therapy, this situation can limit the beneficial effects of aPDT [32]. Thus, our results should not be applied to multi-rooted teeth in other studies.

\section{Conclusion}

A single application of aPDT may not show additional benefits to UPD in clinical periodontal parameters for treating chronic periodontitis in single-rooted teeth among type 2 diabetic patients.
Compliance with ethical standards Each subject provided informed consent after a thorough explanation of the nature, risks, and benefits of the clinical investigations. The study protocol was approved by the Institutional Review Board at São José dos Campos Dental School, UNESP - São Paulo State University (617.795).

\section{References}

1. Chapple ILC, Genco R, on behalf of the working group 2 of the joint EFP/AAP workshop (2013) Diabetes and periodontal diseases: consensus report of the Joint EFP/AAP Workshop on Periodontitis and Systemic Diseases. J Periodontol 84:S106S112. doi:10.1902/jop.2013.1340011

2. International Diabetes Federation (2015) Diabetes Atlas - Seventh Edition. Brussels, Belgium.

3. Preshaw PM, Alba AL, Herrera D, Jepsen S, Konstantinidis A, Makrilakis K, Taylor R (2012) Periodontitis and diabetes: a twoway relationship. Diabetologia 55:21-31. doi:10.1007/s00125-0112342-y

4. Cobb CM (1996) Non-surgical pocket therapy: mechanical. Ann Periodontol 1:443-490. doi:10.1902/annals.1996.1.1.443

5. Westfelt E, Rylander H, Blohmé G, Jonasson P, Lindhe J (1996) The effect of periodontal therapy in diabetics. Results after 5 years. J Clin Periodontol 23:92-100

6. Kiran M, Arpak N, Unsal E, Erdogan MF (2005) The effect of improved periodontal health on metabolic control in type 2 diabetes mellitus. J Clin Periodontol 32:266-272. doi:10.1111/j.1600-051 X.2005.00658.x

7. Singh S, Kumar V, Kumar S, Subbappa A (2008) The effect of periodontal therapy on the improvement of glycaemic control in patients with type 2 diabetes mellitus: a randomized controlled clinical trial. Int J Diabetes Dev Ctries 28:38-44. doi:10.4103/09733930.43097

8. Koromantzos PA, Makrilakis K, Dereka X, Katsilambros N, Vrotsos IA, Madianos PN (2011) A randomized, controlled trial on the effect of non-surgical periodontal therapy in patients with type 2 diabetes. Part I: effect on periodontal status and glycaemic control. J Clin Periodontol 38:142-147. doi:10.1111/j.1600-051 X.2010.01652.X

9. Grellmann AP, Sfreddo CS, Maier J, Lenzi TL, Zanatta FB (2016) Systemic antimicrobials adjuvant to periodontal therapy in diabetic subjects: a meta-analysis. J Clin Periodontol. doi: 10.1111 /jcpe.12514

10. Bower RC (1979) Furcation morphology relative to periodontal treatment. Furcation root surface anatomy J Periodontol 50:366374. doi:10.1902/jop.1979.50.7.366

11. Brayer WK, Mellonig JT, Dunlap RM, Marinak KW, Carson RE (1989) Scaling and root planing effectiveness: the effect of root surface access and operator experience. J Periodontol 60:67-72. doi:10.1902/jop.1989.60.1.67

12. Feres M, Haffajee AD, Allard K, Som S, Goodson JM, Socransky SS (2012) Antibiotic resistance of subgingival species during and after antibiotic therapy. J Clin Periodontol 29:724-735

13. Engebretson S, Kocher T (2013) Evidence that periodontal treatment improves diabetes outcomes: a systematic review and metaanalysis. J Periodontol 84:S153-S163. doi:10.1902 /jop.2013.1340017

14. Wilson M, Dobson J, Sarkar S (1993) Sensitization of periodontopathogenic bacteria to killing by light from a lowpower laser. Oral Microbiol Immunol 8:182-187

15. Al-Zahrani MS, Austah ON (2011) Photodynamic therapy as an adjunctive to scaling and root planing in treatment of chronic periodontitis in smokers. Saudi Med J 32:1183-1188 
16. Andersen R, Loebel N, Hammond D, Wilson M (2007) Treatment of periodontal disease by photodisinfection compared to scaling and root planing. J Clin Dent 18:34-38

17. Berakdar M, Callaway A, Eddin MF, Ross A, Willershausen B (2012) Comparison between scaling-root-planing (SRP) and SRP/photodynamic therapy: six-month study. Head Face Med 8:12-25

18. Braun A, Dehn C, Krause F, Jepsen S (2008) Short-term clinical effects of adjunctive antimicrobial photodynamic therapy in periodontal treatment: a randomized clinical trial. J Clin Periodontol 35: 877-884. doi:10.1111/j.1600-051X.2008.01303.x

19. Campos GN, Pimentel SP, Ribeiro FV, Casarin RC, Cirano FR, Saraceni CH, Casati MZ (2013) The adjunctive effect of photodynamic therapy for residual pockets in single-rooted teeth: a randomized controlled clinical trial. Lasers Med Sci 28:317-324. doi:10.1007/s10103-012-1159-3

20. Lulic M, Leiggener Görög I, Salvi GE, Ramseier CA, Mattheos N, Lang NP (2009) One-year outcomes of repeated adjunctive photodynamic therapy during periodontal maintenance: a proof-ofprinciple randomized controlled clinical trial. J Clin Periodontol 36:661-666. doi:10.1111/j.1600-051X.2009.01432.x

21. Moreira AL, Novaes AB Jr, Grisi MF, Taba M Jr, Souza SL, Palioto DB, de Oliveira PG, Casati MZ, Casarin RC, Messora MR (2014) Antimicrobial photodynamic therapy as an adjunct to non-surgical treatment of aggressive periodontitis: a split-mouth randomized controlled trial. J Periodontol 86:376-386. doi:10.1902 /jop.2014.140392

22. Al-Zahrani MS, Bamshmous SO, Alhassani AA, Al-Sherbini MM (2009) Short-term effects of photodynamic therapy on periodontal status and glycemic control of patients with diabetes. J Periodontol 80:1568-1573. doi:10.1902/jop.2009.090206

23. Macedo Gde O, Novaes AB Jr, Souza SL, Taba M Jr, Palioto DB, Grisi MF (2014) Additional effects of aPDT on nonsurgical periodontal treatment with doxycycline in type II diabetes: a randomized, controlled clinical trial. Lasers Med Sci 29:881-886. doi:10.1007/s10103-013-1285-6
24. Moher D, Hopewell S, Schulz KF, Montori V, Gøtzsche PC, Devereaux PJ, et al. CONSORT 2010 explanation and elaboration: updated guidelines for reporting parallel group randomised trials. J Clin Epidemiol. 63:e1-37. doi: 10.1016/j.jclinepi.2010.03.004

25. Armitage GC (1999) Development of a classification system for periodontal diseases and conditions. Ann Periodontol 4:1-6

26. Julius SA (2004) Sample sizes for clinical trials with normal data. Statist Med 23:1921-1986

27. Sigusch BW, Engelbrecht M, Völpel A, Holletschke A, Pfister W, Schütze J (2010) Full-mouth antimicrobial photodynamic therapy in Fusobacterium nucleatum-infected periodontitis patients. J Periodontol 81(7):975-981. doi:10.1902/jop.2010.090246

28. Betsy J, Prasanth CS, Baiju KV, Prasanthila J, Subhash N (2014) Effect of antimicrobial photodynamic therapy in the management of chronic periodontitis: a randomized controlled clinical trial. J Clin Periodontol 41(6):573-581. doi:10.1111/jcpe.12249

29. Yilmaz S, Kuru B, Kuru L, Noyan U, Argun D, Kadir T (2002) Effect of gallium arsenide diode laser on human periodontal disease: a microbiological and clinical study. Lasers Surg Med 30(1):60-66

30. Polansky R, Haas M, Heschl A, Wimmer G (2009) Clinical effectiveness of photodynamic therapy in the treatment of periodontitis. $\mathrm{J}$ Clin Periodontol 36(7):575-580

31. Rühling A, Fanghänel J, Houshmand M, Kuhr A, Meisel P, Schwahn C, Kocher T (2010) Photodynamic therapy of persistent pockets in maintenance patients - a clinical study. Clin Oral Investig 14(6):637-644. doi:10.1007/s00784-009-0347-4

32. Luchesi VH, Pimentel SP, Kolbe MF, Ribeiro FV, Casarin RC, Nociti FH Jr, Sallum EA, Casati MZ (2013) Phtodynamic therapy in the treatment of class II furcation: a randomized controlled clinical trial. J Clin Periodontol 40(8):781-788. doi:10.1111 /jcpe. 12121

33. Nesse W, Linde A, Abbas F, Spijkervet FK, Dijkstra PU, de Brabander EC, Gerstenbluth I, Vissink A (2009) Dose-response relationship between periodontal inflamed surface area and HbA1c in type 2 diabetics. J Clin Periodontol 36(4):295-300. doi:10.1111/j.1600-051X.2009.01377.x 